\title{
INHIBITORY MECHANISMS OF ISOPRENALINE IN THE GUINEA-PIG TAENIA COL.I
}

\author{
Hisako WATANABE* \\ Department of Physiology, Faculty of Medicine, \\ Kvashu University, Fukwoka 812, Japan
}

Accepted December 23, 1975

\begin{abstract}
The beta-receptor stimulating effect of isoprenaline on the spontaneous activities of the guinea-pig taenia coli was investigated in the presence of an alphareceptor blocking agent, phentolamine $\left(2 \times 10^{-6} \mathrm{M}\right)$. Substitution of the external $\mathrm{Na}$ ion with $\mathrm{L}, \mathrm{i}$, choline, tris-hydroxymethyl aminomethane or $\mathrm{K}$ ion greatly reduced the inhibitory effect of isoprenaline. A treatment with ouabain $\left(4 \div 10^{-6} \mathrm{M}\right)$ also had effects similar to those of $\mathrm{Na}$ removal. The spontaneous activity was transiently suppressed when $5.9 \mathrm{mM} \mathrm{K}$ ion was re-admitted into $\mathrm{K}$-free solution, and this suppressing effect

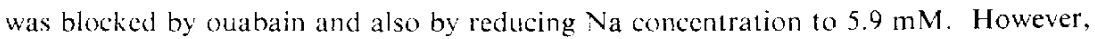
isoprenaline retained its effects in $\mathrm{K}$-free solution containing normal $\mathrm{Na}$ concentration or $5.9 \mathrm{mM} \mathrm{Na}$. The relaxation by isoprenaline in these solutions was hardly reduced by ouabain $\left(4: 10^{-6} \mathrm{M}\right)$. These observations suggest that the beta-receptor stimulating effects of isoprenaline are partly mediated through an activation of the Na-pump and partly through some other mechanism which is inactivated when the preparation is deprived of $\mathrm{Na}$ or when the membrane is depolarized.
\end{abstract}

It has been speculated that adrenaline may stimulate an electrogenic Na-pump in the guinea-pig taenia coli, leading to hyperpolarization of the cell membrane and to inhibition of the spontaneous activity (1). Since both the alpha-adrenoceptor and the betaadrenoceptor are involved in inhibitory actions of catecholamines in the taenia coli (2-4), these two actions should be differentiated. The inhibition due to an activation of the alphaadrenoceptor is a result of an increase in $\mathrm{K}$ and $\mathrm{Cl}$ conductances of the membrane $(2,5)$. However, the inhibitory mechanism through activation of the beta-adrenoceptor is not entirely clear.

There is one hypothesis that the effect of an activation of the beta-adrenoceptor by catecholamines is mediated by an increase of cyclic adenosine $3^{*}, 5^{\prime}$-nonophosphate $(6,7)$. Formation of cyclic AMP may lead to further metabolic changes. Thus, the Na-pump may be activated when intracellular cyclic AMP is increased by an activator of the betaadrenoceptor, such as isoprenaline. The aim of the present experiments was to test such a possibility and studies were based on actions of isoprenaline on the spontaneous activity of the guinea-pig taenia coli under the conditions which are known to block the Na-pump. It has been reported that in the taenia coli, as in other tissues, removal of the external $\mathrm{K}$ ion suppresses the Na-pump and that re-admission of $\mathrm{K}$ activates the pump and inhibits the spontaneous activity $(8-11)$. Therefore, the inhibitory action of $\mathrm{K}$ ion was also compared

* Present Address: Department of Anatomy, Factilty of Medicine, Tokyo Lnisersity, Tokyo 113. Japan 
with that of isoprenaline.

\section{MATERIALS AND METHODS}

Guinea-pigs were stunned and bled and pieces of the taenia coli (about $25 \mathrm{~mm}$ in length) were dissected. The muscle strip was suspended in an organ bath ( $3 \mathrm{ml}$ capacity), and attached to a strain gauge transducer under a passive tension of about $0.2 \mathrm{~g}$. Mechanical responses were isometrically recorded and displayed on a potentionetric pen recorder.

Physiological saline (modified Krebs) solution had the following composition (mM): $\mathrm{NaCl} 135.5, \mathrm{KHCO}_{3} 5.9, \mathrm{CaCl}_{2} 2.5, \mathrm{MgCl}_{2} 1.2$ and glueose 11.5 . A gas mixture of $3 \% \mathrm{CO}_{2}$ and $97 \% \mathrm{O}_{2}$ was bubbled through the solution and the temperature of solution in the organ bath was kept constant at $37^{\circ} \mathrm{C}$. Since Na-free solution contained $5.9 \mathrm{mM} \mathrm{HCO}$ as $\mathrm{KHCO}_{5}$, a concentration of $\mathrm{HCO}_{3}$ was maintained at $5.9 \mathrm{mM}$ in all solutions. Li, choline or trishydroxymethyl aminomethane (THAM) was used as a substitute for $\mathrm{Na}$ in $\mathrm{Na}$-free or Nadeficient solutions. When choline was used, $10^{-6} \mathrm{M}$ atropine sulphate (Tanabe Seiyaku) was always added to the solution to block a cholinergic effect. In the preliminary experiments, it was found that removal of $\mathrm{HCO}_{3}$ reduced the potency of isoprenaline. Therefore, when $\mathrm{K}$ ion was removed, $5.9 \mathrm{mM} \mathrm{KHCO}_{3}$ was substituted with an equimolar $\mathrm{NaHCO}_{3}$ and a concentration of $\mathrm{Na}$ was maintained at $5.9 \mathrm{mM}$ throughout. $\Lambda$ specific blocking agent of the alpha-action of catecholamines, phentolamine methanesulphate (Ciba) was added to all test solutions at a concentration of $2 \times 10^{-6} \mathrm{M}$, except for the experiments in which the eflect of isoprenaline was compared with that of adrenaline (Fig. 4).

Solutions were allowed to flow continuously through the organ bath at a constant rate of $1 \mathrm{ml} / \mathrm{min}$. Since the capacity of organ bath was $3 \mathrm{ml}$, a change of test solution took more than 3 min at this flow rate. Isoprenaline hydrochloride (Nikken Kagaku) was slowly injected into a inlet vinyl tube, through which the solution entered into the organ bath, usually to give a final concentration of $10^{-6} \mathrm{M}\left(2.5 \times 10^{-7} \mathrm{~g} / \mathrm{ml}\right)$ in the organ bath. Thus, this concentration was present only at the time shortly after injection and was thereafter progressively diluted.

The double sucrose-gap method was used in some experiments for simultaneous recording of electrical and mechanical responses. This method was the same as previously described $(5)$.

\section{RESLLTS}

Effects of removal of the extermal Na ion

It is known that spontaneous mechanical activity usually appears rhythmically when the Krebs solution contains $15.5 \mathrm{mM} \mathrm{HCO}$ (12). However, the activity was of ten continuous when the $\mathrm{HCO}_{3}$ conceniration of the medium was reduced to $5.9 \mathrm{mM}$. When the external Na concentration was reduced, the active tension increased, particularly for first 10-20 min. At a Na concentration of less than $5 \mathrm{mM}$, the small fluctuations in the tension asually disappeared after $10-20 \mathrm{~min}$ (Fig. 1 ).

When the external Na concentration was reduced, the potency of isoprenalino in pro- 
ducing relaxation did not change significantly until the concentration was less than $10 \mathrm{mM}$. However, the relaxation by isoprenaline became short-lasting and incomplete when the $\mathrm{Na}$ concentration was lowered to less than $5 \mathrm{mM}$. Fig. 1 shows effects of isoprenaline in $\mathrm{Na}$-free solutions, $\mathrm{Na}$ being replaced with $\mathrm{Li}$ (a), choline (b) and THAM (c). The effect of isoprenaline was very weak or absent. In other similar experiments, it was found that the effect of isoprenaline was gradually reduced with time of the exposure to Na-free solution. When there were still fluctuations in tension at an early phase in Na-free solution, isoprenaline usually produced significant relaxation, but after disappearance of the fluctuation, the relaxation by isoprenaline was observed to be very small or was even blocked.

Fig. 2 shows the mechanical (upper trace) and electrical activity (lower trace) in Krebs solution (a) and in Na-free solu-

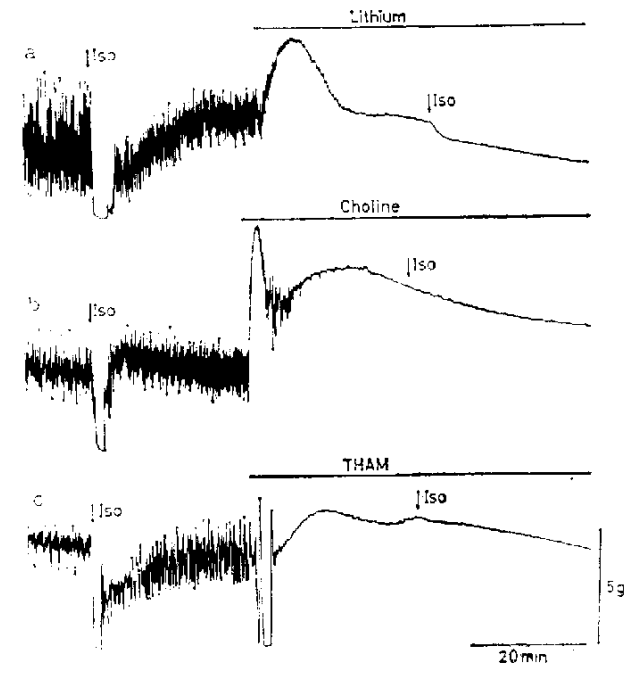

FIG. 1. Effects of isoprenaline $\left(10^{-6} \mathrm{M}\right)$ on mechanical activities of the guinea-pig tacnia coli, in normal solution and in $\mathrm{Na}$ free solutions. $\mathrm{Na}$ was replaced with lithium (a), choline (b) and tris-hydroxymethyl aminomethane (THAM) (c) in different preparations. Superfusion of $\mathrm{Va}$-free solution is indicated by horizontal bars. All solution contained phentolamine $\left(2 \times 10^{-6} \mathrm{M}\right)$. Note that the effect of isoprenaline was weak or blocked entirely in Na-free solutions.

tion (b), recorded with the double sucrose-gap method. In Krebs solution, isoprenaline slightly hyperpolarized the membrane without a large change in the membrane resistance

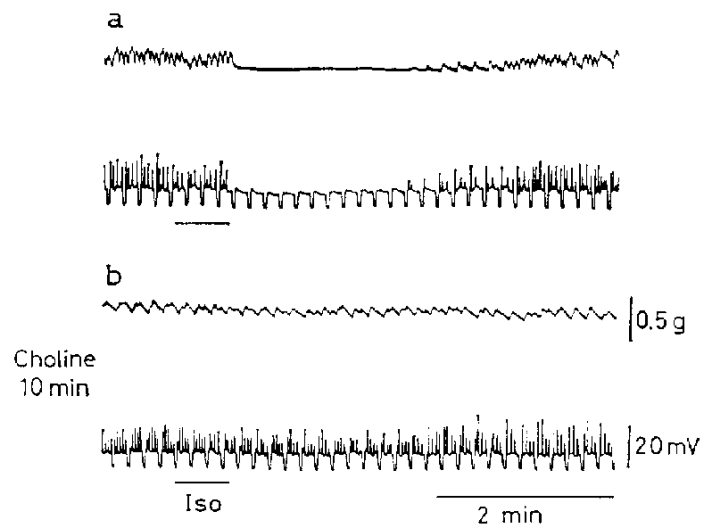

FIG. 2. Mechanical (top trace) and elcetrical (bottom trace) activities recorded with the double sucrose-gap method. Constant current pulse of $2.5 \mathrm{sec}$ in duration was applied every $10 \mathrm{sec}$ to measure changes in the membrane resistanes. Isoprenaline $\left(10^{-1 \mathrm{M}} \mathrm{M}\right)$ was applicel for $35 \mathrm{sec}$ (indicated by horizontal bars) in normal solution (a) and 10 min after in Na-free choline solution (b). 
and blocked the spontaneous electrical and mechanical activities, as already reported (4). When Nafree solution (choline substitution) was introduced, the membrane uds depolarized by about $10 \mathrm{mV}$, but was followed by a gradual repolariation. However, the membrane potential never returned to a control level but remained aboul the $5 \mathrm{mV}$ depolarized state. In the Na-free solution, the spike activity continued, or re-alppeared after transient disappearance, during the depolarized phase. The effect of isoprenaline almost disappeared after about $10 \mathrm{~min}$ exposure to the $\mathrm{Nal}$-free solution (Fig. 2b).

When $\mathrm{K}$ ion was substituted for Na ion, the effect of isoprenaline was reduced (Fig. $3 a)$, as in other Na-free solutions. However, in preparations depolarized by excess $K$, the magnitude of relaxation by isoprenaline was less dependent on concentrations of the external $\mathrm{Na}$ ion. When $\mathrm{Li}$, choline or THAM was substituted for $\mathrm{Na}$, isoprenaline relaxed the preparation almost entirely when the mediun contained 5.9-10 $\mathrm{mM}$ Na (see Fig. 8a). On the other hand, the effect of isoprenaline in K-solution containing $10 \mathrm{mM} \mathrm{Na}$ was observed to be only slightly larger than when in a Na-free K-solution (Fig. 3b).

Relaxation by isoprenaline was markedly suppressed in Na-free solution, while that by adrenaline was little affected (Fig. 4). When the tissue was exposed to Na-free solution for more than $1 \mathrm{hr}$, the effect of adrenaline was aiso decreased.
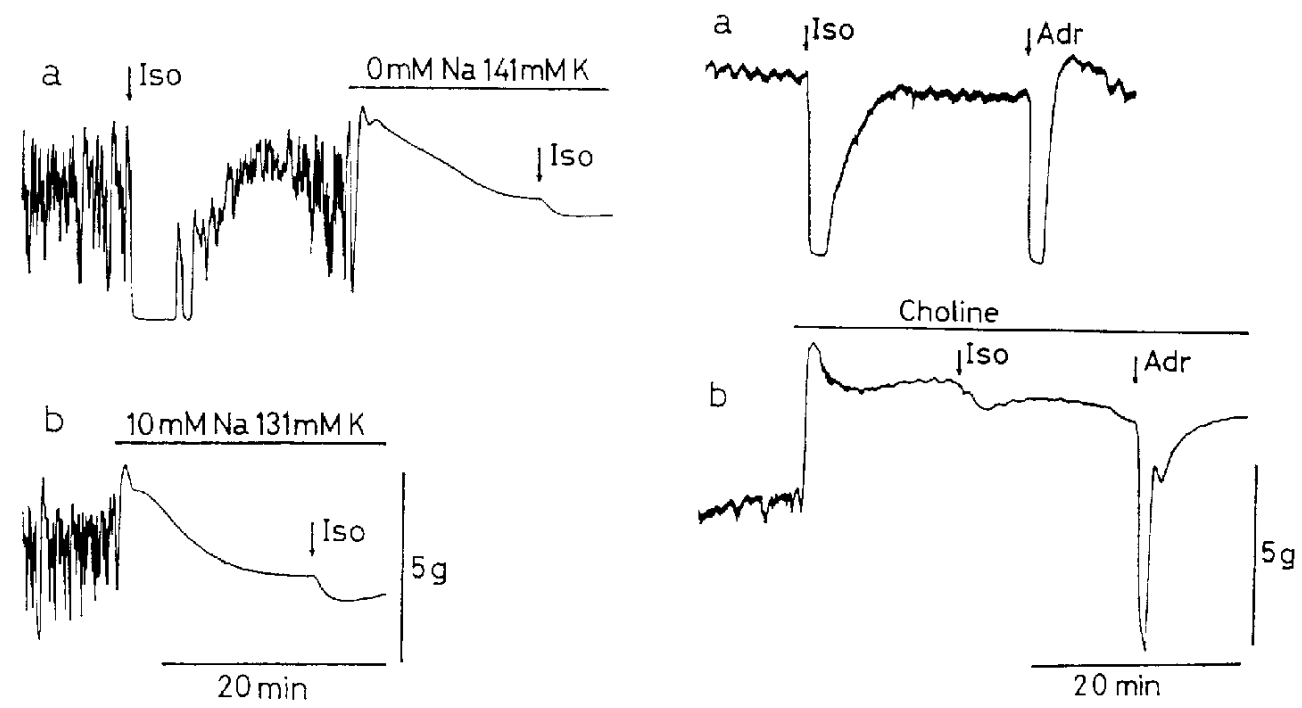

Fri. 3. Effects of isoprenaline (10" $\mathrm{M})$ applied at arrows in solution containing () $\mathrm{mM} \mathrm{Na}$ and $14 \mathrm{lmM} \mathrm{K}$ (a) and in solution containing $10 \mathrm{mM} \mathrm{Na}$ and 131 17) $\mathrm{K}$ (b), other ions being kept the same as in Krebs solution. Changing test solution is indicated by horizontal hars.

Eig. 4. Lffects of isoprenaline $\left(10^{-6} \mathrm{M}\right)$ and adrenaline $(10$ " $\mathrm{M})$ in Va-frec solution (choline substitution). Here the solution did not contain phentolamine. a : control response in Krebs solution, b: Krebs solution was replaced with choline solution as indicaled by the horizontal bar. Note that relaxation by isoprenaline was reduced, but that by adrenaline was litile affected in Na-frec solution. 


\section{Effects of ouchain}

When preparations were treated with ouabain $\left(4<10^{-6} \mathrm{M}\right)$, the tension increased transiently for aboul $20 \mathrm{~min}$, then gradually decreased, and the activity finally ceased after $40-50 \mathrm{~min}(11,13)$. The inhibitory action of isoprenaline was reduced by ouabain (Fig. $5 \mathrm{a}$ ). After a preparation was completely relaxed by a prolonged treatment with ouabain, the

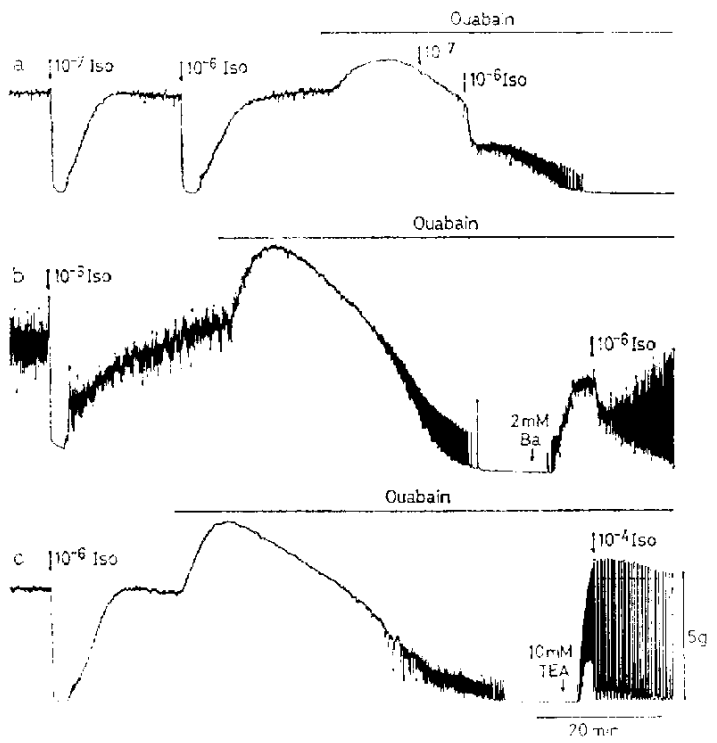

FIG. 5. Effects of isoprenaline in the presence of olabain (4 $\left.10^{\circ} \mathrm{M}\right)$ which is indicated by horizontal bars. Concentrations of isoprenaline are in molar units. In (b) $2 \mathrm{mM} \mathrm{Ba}$ and in (c) $10 \mathrm{mM}$ tetraethylammonium chloride (TEA) was added to Krebs solution to initiate the activity in the presence of ouabain, and then effect of isoprenaline was tested (in (c) concentration of isoprenaline was increased to $10^{-+} \mathrm{M}$ ). Note that relaxation by isoprenaline was weakened after ouabain treatment.

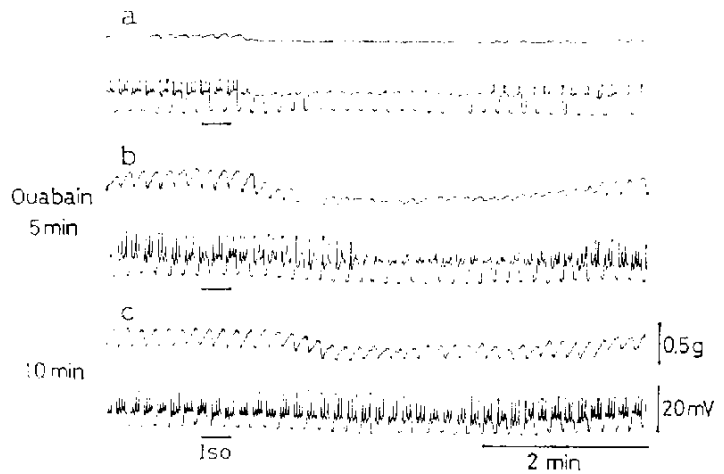

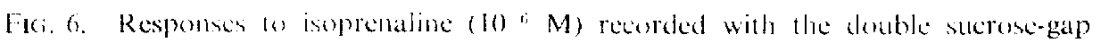
method. at: hormal solution, b: 5 min after and $c$ : 10 mith after in ouabian (4 $10^{- \text {th }}$ M) solution. Top: mechanical and bottom: clectrical recording. Constant current pulses (2.5 sec duration) werc applied throughou every $10 \mathrm{sec}$. Note suppression of isoprenaline effect by ouabain tratement. 
activity was initiated by an application of $2 \mathrm{mM} \mathrm{Ba}$ (b) or $10 \mathrm{mM}$ tetraethylammonium chloride (TEA) (c), and then isoprenaline $\left(10^{-6} \mathrm{M}\right.$ in (b) and $10^{-4} \mathrm{M}$ in (c)) was applied in the presence of ouabain $\left(4 \times 10^{-6} \mathrm{M}\right)$. Under this condition, the effect of isoprenaline was very weak or not apparent.

Simultaneous recording of mechanical and electrical responses to isoprenaline $\left(10^{-6} \mathrm{M}\right)$ is shown in Fig. 6. Results similar to those obtained by the mechanical recording in the organ bath (Fig. 5) were obtained with the double sucrose-gap method; i.e., as shown in Fig. $6 \mathrm{~b}$ and $\mathrm{c}$, the effect of isoprenaline was reduced by a treatment with ouabain $\left(4 \cdots 10^{-i_{3}}\right.$ $\mathrm{M}$ ), which depolarized the membrane by about $5 \mathrm{mV}$ and increased the spike activity.

Effects of removal of the external $K$ ion

A removal of the external $\mathrm{K}$ ion is known to suppress the Na-punp in the smooth muscles (8-11). Isoprenaline $\left(10^{-6} \mathrm{M}\right)$ produced a large relaxation in K-free solution, however, the speed of relaxation was slow, the tension was usually not reduced to zero, and a minor fluctuation in tension often remained during the relaxation (Fig. 7b). When 5.9 $\mathrm{mM} \mathrm{K}$ ion was re-admitted to the external medium, the muscle was completely relaxed (c). as previously reported for the taenia coli (11) and for the carotid artery (14). This relaxation by $\mathrm{K}$ ion was blocked by a treatment with ouabain $\left(4 \times 10^{-6} \mathrm{M}\right)$ (d), although the effect of isoprenaline was not abolished by the ouabain treatment, it was nevertheless slightly reduced (e).

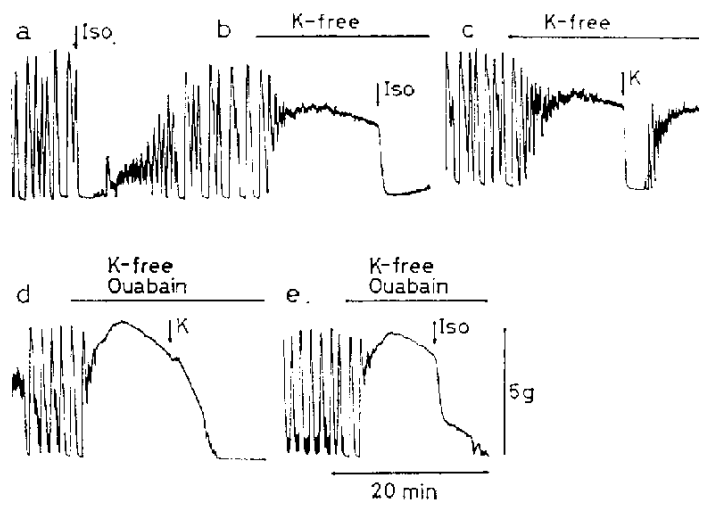

Fig. 7. Responses to isoprenaline $\left(10^{-5} \mathrm{M}\right)$ and to addition of $\mathrm{K}$ ion $(5.9 \mathrm{~m} \mathrm{M})$ in K-free solution, in the absence $(a, b, c)$ and in the presence $(d, c)$ of ouabain (4. $\left.10^{-6} \mathrm{M}\right)$.

\section{Effects of a combination of Na-deficient, $K$-free and ouabain}

When $\mathrm{Na}$ ion of more than $5.9 \mathrm{mM}$ was present, isoprenaline produced a good relaxation, although the magnitude was less than in the presence of the normal concentration of $\mathrm{Na}$ ion. This relaxation was seen to a greater extent when $\mathrm{Na}$ was substituted with THAM than when Nal was substituted with choline. The effect of isoprenaline in Na-deficient solution was more or less the same in both the presence (Fig. 8a) and absence of the external $\mathrm{K}$ ions (Fig. 8b). However, the relaxaing action of re-admission of $5.9 \mathrm{mM} \mathrm{K}$ after a pretreatment 


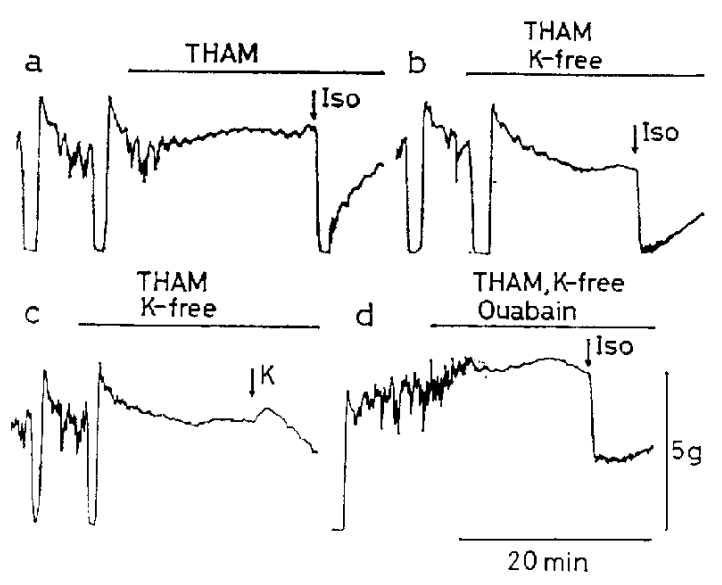

FIG. 8. Effects of isoprenaline $\left(10^{\circ} \mathrm{M}\right)$ in $5.9 \mathrm{mM} \mathrm{Na}$ (THAM substitution) (a), $0 \mathrm{mM} \mathrm{K}, 5.9 \mathrm{mM} \mathrm{Na}(\mathrm{b})$ and $0 \mathrm{mM} \mathrm{K}, 5.9 \mathrm{mM} \mathrm{Na}$ containing oubain $\left(4 \times 10^{-\mathrm{b}}\right.$ M) (d). In (c), $\mathrm{K}$ ion (5.9 mM) was added to $\mathrm{K}$-free $5.9 \mathrm{mM} \mathrm{Na}$ solution. Note that re-admission of $\mathrm{K}$ did not produce relaxation, while a significant relaxation was seen with isoprenaline.

with K-free solution was completely suppressed or reversed to an excitatory action in Nadeficient ( $5.9 \mathrm{mM} \mathrm{Na}$ ) solution (Fig. 8c). When the solution contained more than $10 \mathrm{mM}$ $\mathrm{Na}$, or when $\mathrm{K}$ ion was applied after a short exposure (within $10 \mathrm{~min}$ ) to $5.9 \mathrm{mM} \mathrm{Na}$ solution, relaxation was produced by re-admission of the external $K$ ion. On the other hand, the inhibitory effect of isoprenaline was not blocked even in $\mathbf{K}$-free, Na-deficient solution containing ouabain (Fig. 8d), as it was in K-free solution containing a normal concentration of $\mathrm{Na}$ ion and ouabain (Fig. 7e).

\section{DISCUSSION}

The beta-stimulating effect of isoprenaline was found to be suppressed by a removal of the external $\mathrm{Na}$ ion and by a treatment with ouabain. In the organ bath experiments, the relaxing effect of isoprenaline gradually disappears with exposure to Na-free solution. It may be that the effect of isoprenaline is weakened as the intracellular Na concentration is lowered. Since the activity of Na-punp is suppressed by lowering intracellular Na concentration and by treatment with ouabain $(15,16)$, the Na-pump may be involved in the inhibitory mechanism of isoprenaline in the guinea-pig taenia coli. This possibility has also been suggested for the action of isoprenaline on the rabbit pulmonary artery (17). The relixation due to stimulation of the alpha-adrenergic receptor is less dependent on the presence of $\mathrm{Na}$ ion, because adrenaline, which has a stronger stimulant action of the alphareceptor than isoprenaline, can produce relaxation even after disappearance of the effect of isoprenaline in $\mathrm{Na}$ free solution.

In contrast, in the rat uterine smooth muscle, participation of the Na-pump has been rejected because adrenaline and other adrenergic beta-receptor stimulants still cause hyperpolarization and suppress action potentials after complete replacement of $\mathrm{Na}$ with $\mathrm{Li}$, 
THAM or sucrose (18). Isoprenaline is also effective on the mouse myometrium even after 12 hours exposure to Natfrec solution (19). Another difierence between the guinea-pig taenia coli and the rat uterine muscle in the response to isoprenaline is found in K-rich medium. In the tatenia coli, the contracture produced by isotonic $\mathrm{K}$ solution is little depressed by catecholamines, as observed by Axelsson et al. (20) and by Inatomi et al (21), while in the rat myometrium, isoprenaline can cause marked relaxation in the depolarized condition through activation of the beta-adrenoceptor $(2,22)$. Based on observations on the depolarized rat myometrium, the latter author has proposed a hypothesis that isoprenaline activates a Ca-accummulating mechanism similar to that in the sarcoplasmic reticulum in the striated muscle and lowers the concentration of myoplasmic free $\mathrm{Ca}$ ion. Another possibility has also been suggested that in the myometrium, isoprenaline activates a Capump which extrudes Ca from the cell $(23,24)$.

Removal of the external $\mathrm{K}$ ion depolarizes the membrane increasing the spontaneous activity while re-admission of $\mathrm{K}$ ion hyperpolarizes the membrane suppressing the activity, and these changes are blocked by ouabain. These effects appear to be the result of the fact that the electrogenic Na-pump is suppressed by removal of $\mathrm{K}$ and activated by re-admission of $K(8-11)$. The disappearance of the inhibitory effect of K-re-admission in Na-deficient solution also supports the thesis of involvement of the Na-pump. On the other hand, the effect of isoprenaline is only slightly reduced in $\mathrm{K}$-frec solution containing $5.9 \mathrm{mM} \mathrm{Na}$ and $4: 10^{-i j} \mathrm{M}$ ouabain. Relaxation by isoprenaline in $\mathrm{K}$-free medium has also been reported For the rat myometrium (25) and for the cat carotid artery (14). It is likely that under the condition in which the Na-pump is suppressed, some other mechanism, which reduces the intracellular free Ca concentration, is operating in the inhibitory mechanisim of isoprenaline. Although this mechanism may also be involved under normal conditions, it seems that in the guinea-pig taenia coli, this process is inactivated when the preparation is deprived of $\mathrm{Na}$ or when the membrane is depolarized. It has been reported that isoprenaline increases intracellular concentration of cyclic AMP and that this effect and relaxation by isoprenaline are blocked when the external $\mathrm{Na}$ is completely replaced by $\mathrm{K}$ ion (21). Therefore, cyclic AMP may be involved in the mechanism reducing the intracellular free Ca concentration.

Acknowledgements: Gratitude is due to Professors N. Toida and Y. Oomura for their encouragement and for the privilege of working under their supervision. Thanks are also due to Professor T. Tomita and Dr. Y. Sakamolo, Fukuoka Lniversity, for their pertinent advice and assistance during this work.

\section{REFLRENC'ES}

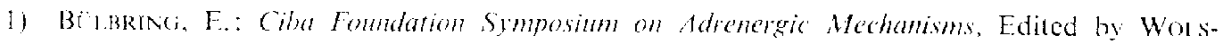
TENHOLME, G.E.W. AND OCOANOR, M., p. 275, Churchhill J.td, London (1960)

2) Jevininon, D.H. and Morton, I.K.M.: J. Physiol. 188, 387 (1967)

3) Andersson, R. and MohmF-L lindhoim, F. : Acta physiol. acand. 77, 372 (1969)

4) Bílbringi, E. and Tomita. T.: Pror. R. Sor. B. 172, 103 (1969)

5) Bílbrivg, E. AND IOMLA, T.: Proc. R. Soc, B. 172, 89 (1969)

6) Andizsson, R, ANo Mohmi-Lendhoim, F. : Acta phisiol. scand. 79, 244 (1970) 


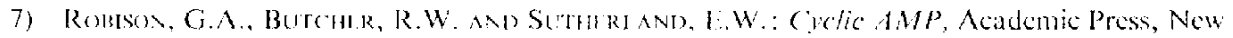
York (1971)

8) TAYlok, G.S., PATON, D.M. ANI DANil 1, L.t:. Life Sci. 8, 769) (1960)

9) Taylor, G.S., Paton, D.M. and Daniel. E.E.: J. gen. Physiol. 56, 360 (1970)

10) Castefis, R., Droogmans, G. and Hendrickx, H.: I. Physiol. 217, 297 (1971)

11) Tomita, T. and Yamanoto, T.: J. Physiol. 212, 851 (1971)

12) Golenhoffin, K.: Smooth Muscle, Edited by Bïtrring, E., Bradinci, A.F., Joni:s, A.W. and TOMIA, T., p. 316 Edward Arnold, London (1970)

13) Casteel.s, R.: J. Physiol. 184, 131 (1966)

14) Bose, D. And Innes, I.R : Canad. J. Plysiol. Pharmacol. 50, 378 (1972)

15) Kerkut, G.A. AND York, B.: The Electrogenic Solimm Pimp. Scientechnica, Bristol (1971)

16) Thomas, R.C.: Physiol. Ri' 52,563 (1972)

17) Somlyo, A.V., Haebsifr, (i. and Somlyo, A.P.: Science 169, 490 (1970)

18) Marshall, J.Ml:: Fedil Proc. 27, 115 (1968)

19) Magariblichi, T. ANd Osa, T. Japan. I. Physiol. 21, 627 (1971)

20) Axelsson, J., Holmberg, B. and Hocibleg, G.: Life Sci. 4, 817 (1965)

21) Inalomi, N., Takayanagi, I., UChida, M. and Takagi, K.: Europ. J. Pharmacol. 26, 73 (1974)

22) S(HLl, H.O.: Brit. J. Pharmacol. 31, 578 (1967)

23) Kroegir, E.A. and Marshall, J.M.: Am. J. Physiol. 225, 1339 (1973)

24) Marshatl, J.M. and Krofger, E.A.: Phil. Tians. R. Soc. B. 265, 135 (1973)

25) Davifi, E.E., Paton, D.M., Taylok, G.S. and Hodison, B.J.: Fedh Proc, 29, 1410 (1970) 